\title{
A THEORETICAL STRUCTURE-AFFINITY RELATIONSHIP STUDY OF SOME CANNABINOID DERIVATIVES
}

\author{
JUAN S. GÓMEZ-JERIA, ${ }^{a, b *}$ FRANCISCO SOTO-MORALES, ${ }^{a}$ JORGE RIVAS, ${ }^{a}$ AND \\ ALEJANDRA SOTOMAYOR .
}

a. Universidad de Chile, Facultad de Ciencias, Departamento de Química. Casilla 653 Santiago, Chile.

b. Programa de Doctorado en Fisicoquímica Molecular, Universidad Andrés Bello, Facultad de Ecología y Recursos Naturales República 275, Santiago, Chile.

(Received: 12 June - Accepted: 13 November 2007)

\begin{abstract}
A ZINDO/1 quantum-chemical structure-affinity relationship study with the KPG model is presented for the in vitro interaction of a group of classical, indolederived and aminoalkylindole-derived cannabinoids with $C B_{1}$ and $C B_{2}$ receptors. From this work the following conclusions are obtained. $C B_{1}$ and $C B_{2} C B_{2}$ receptor affinities are regulated by different mechanisms involving orbital and charge control. Nevertheless $C B_{1}$ and $C B$, classical ligands share three common features: a hydrogen bond to a lysine (for $C B_{1}$ ) or serine (for $C B_{2}$ ), a fully aromatic ring and a branched carbon side chain. In the case of indole-derived and aminoalkylindolederived cannabinoids orientation and alignment rules have been defined as a basis for the comparison of noncongeneric molecules. In this way it was possible to associate the location of molecular fragments of these systems with known molecular systems such as classical cannabinoids. For aminoalkylindoles we have proposed the locus with which they bind to a second receptor site that is available to WIN-55212-2 but not to classical cannabinoids. On the basis of our results we propose a new molecule that should help to discriminate between the above two receptor sites.
\end{abstract}

Keywords: Structure-affinity relationships, QSAR, cannabinoid receptors, ZINDO/1, quantum pharmacology.

\section{INTRODUCTION}

Marijuana is a mixture of leaves, stems, and flowering tops of the Indian hemp plant Cannabis sativa (the genus Cannabis belongs to the family Moraceae). Marijuana has been used as a folk medicine for rheumatism, gout, malaria, and oddly enough, absent-mindedness, and for its psychoactive properties. The stems are an important source of hemp fiber and the seeds are a good source of edible oil. Long known in Central Asia and China, it was described in a Chinese medical compendium traditionally considered to date from 2737 B.C. Its use spread from China to India and then to North Africa and reached Europe at least as early as A.D. 500. The Muslims used it recreationally because alcohol consumption was banned by the Koran. It was the Muslims who introduced hashish - the resin of the plant -, whose popularity spread quickly throughout 12th century Persia and North Africa. In 1545 the Spanish brought hemp to the New World. About 1900 it started to be used as a pleasure-inducing drug in the West ${ }^{1}$. It was reported also that marijuana was sometimes used in folk medicine for treating gonorrhea in Sikkim, India ${ }^{2}$. Marijuana's active components are potentially effective in treating pain, nausea, particularly related to cancer chemotherapy, anorexia in AIDS patients, and other conditions such as glaucoma.

The smoke produced by combustion of marijuana contains, among other chemicals, at least sixty-one different cannabinoids. One of these $\Delta^{9},-$ tetrahydrocannabinol $\left(\Delta^{9}\right.$-THC, 8 in Figure 1$)$ produces most of the classical pharmacological effects of smoked marijuana: changes in mood, perception and motivation. The typical marijuana smoker experiences a high lasting about 2 hours with impairment of cognitive functions, perception, reaction time, learning, and memory.

Up to date two cannabinoid receptors have been described. They belong to the superfamily of G-protein-coupled membrane receptors. In humans, the $C B$ receptor is present primarily in the central nervous system and some peripheral neurons; it is particularly prevalent in the basal ganglia, hippocampus, cerebellum, and cerebral cortex ${ }^{3,4}$. The $C B$, receptor is principally found in the spleen, tonsils, bone marrow and peripheral blood leukocytes ${ }^{5,6}$. The search for an endogenous ligand led to the discovery of $\mathrm{N}$-(2-hydroxyeth yl)arachidonylamide (anandamide) which binds to the $C B_{l}$ receptor with an affinity similar to that of $\Delta^{9}-\mathrm{THC}^{7,8}$. The discovery of anandamide and other $\mathrm{N}$-acylethanolamines in chocolate elicited a controversy about the possibility that the purported rewarding properties of cocoa reflect the presence of this kind of compounds ${ }^{9-12}$.

There are several very different chemical structures that bind to cannabinoid receptors. This fact represents a challenge for the quantum chemist. To gain a deeper physical insight regarding the nature of the interaction of cannabinoids with their receptors, we present here the results of a formal in vitro structureaffinity relationship study carried out for a variety of $C B_{1}$ and $C B_{2}$ ligands.

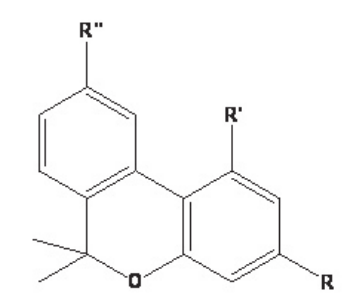

1. $\mathrm{R}=\mathrm{C}_{5} \mathrm{H}_{11}, \mathrm{R}^{\prime}=\mathrm{OH}, \mathrm{R}^{\prime \prime}=\mathrm{CH}_{3}$ 2. $\mathrm{R}=\mathrm{C}\left(\mathrm{CH}_{3}\right)_{2} \mathrm{C}_{6} \mathrm{H}_{13}, \mathrm{R}^{\prime}=\mathrm{OH}, \mathrm{R}^{\prime \prime}=\mathrm{CH}_{3}$ 3. $\mathrm{R}=\mathrm{C}_{5} \mathrm{H}_{11}, \mathrm{R}^{\prime}=\mathrm{OH}, \mathrm{R}^{\prime \prime}=\mathrm{CH}_{2} \mathrm{OH}$ 4. $\mathrm{R}=\mathrm{C}\left(\mathrm{CH}_{3}\right)_{2} \mathrm{C}_{6} \mathrm{H}_{13}, \mathrm{R}^{\prime}=\mathrm{OH}, \mathrm{R}^{\prime \prime}=\mathrm{CH}_{2} \mathrm{OH}$ 5. $\mathrm{R}=\mathrm{C}_{5} \mathrm{H}_{11}, \mathbf{R}^{\prime}=\mathrm{OH}_{1} \mathbf{R}^{\prime \prime}=\mathrm{COOH}$ 6. $\mathrm{R}=\mathrm{C}\left(\mathrm{CH}_{3}\right)_{2} \mathrm{C}_{6} \mathrm{H}_{13}, \mathrm{R}^{\prime}=\mathrm{OH}, \mathrm{R}^{\prime \prime}=\mathrm{COOH}$ 7. $\mathrm{R}=\mathrm{C}\left(\mathrm{CH}_{3}\right)_{2} \mathrm{C}_{6} \mathrm{H}_{13}, \mathrm{R}^{\prime}=\mathrm{OCOCH}_{3}, \mathrm{R}^{\prime \prime}=\mathrm{COOH}$<smiles>[R]C1=CCC2[C@H](C1)c1c(O)cc([R])cc1OC2(C)C</smiles>

10. $\mathbf{R}=\mathrm{C}_{5} \mathrm{H}_{11}, \mathbf{R}^{\prime}=\mathrm{CH}_{2} \mathrm{OH}$ 11. $\mathbf{R}=\mathbf{C}\left(\mathrm{CH}_{3}\right)_{2} \mathrm{C}_{6} \mathrm{H}_{13}, \mathbf{R}^{\prime}=\mathrm{CH}_{2} \mathrm{OH}$ 12. $\mathrm{R}=\mathrm{C}\left(\mathrm{CH}_{3}\right)_{2} \mathrm{C}_{6} \mathrm{H}_{13}, \mathrm{R}^{\prime}=\mathrm{COOH}$

Figure 1. Structure of the classical cannabinoids.

\section{MATERIALS AND METHODS}

As the method has been widely and thoroughly discussed in this Journal and elsewhere ${ }^{13-18}$, we shall present a very general sketch. Starting from the statistical-mechanical definition of the equilibrium constant, and using a set of physically-based approximations, we may derive the following equation containing only drug-related terms:

$$
\begin{aligned}
& \log K=a+b \log M_{D}+c \log \sigma_{D}+d \log \left(I_{1} I_{2} I_{3}\right)+ \\
& \sum_{i}\left[E_{i} Q_{i}+F_{i} S_{i}^{B}+G_{i} S_{i}^{N H}\right]+\sum_{i} \sum_{m}\left[H_{i}(m) D_{i}(m)+J_{i}(m) S_{i}^{B}(m)\right]+ \\
& +\sum_{i} \sum_{m^{\prime}}\left[R_{i}\left(m^{\prime}\right) D_{i}\left(m^{\prime}\right)+T_{i}\left(m^{\prime}\right) S_{i}^{N /}\left(m^{\prime}\right)\right]
\end{aligned}
$$


where $\mathrm{a}, \mathrm{b}, \mathrm{c}, \mathrm{d}$ and $\mathrm{e}$ are constants, $\mathrm{D}$ refers to the drug molecule, $\sigma$ is the symmetry number, $\mathrm{M}$ the drug's molecular mass, is the product of the three moments of inertia about the three principal axes of rotation, and is here the cannabinoid-receptor interaction energy. In our previous studies it has been shown that in the case of orbital contributions, the first, second and third occupied (HOMO, NHOMO and SHOMO respectively) and virtual (LUMO, NLUMO and SLUMO) molecular orbitals (MO) are involved.

The moment of inertia term deserves a comment. We proposed that this term could be expressed in a first approximation as ${ }^{18,19}$.

$$
\log \left(I_{1} I_{2} I_{3}\right)=\sum_{t} \sum_{i} m_{i, t} R_{i . t}^{2}=\sum_{t} O_{t}
$$

where the summation over $\mathrm{t}$ is over the different substituents of the molecule, $m^{i, t}$ is the mass of the $\mathrm{i}$-th atom belonging to the r-th substituent, $R_{\text {. }}$ being its distance to the atom to which the substituent is attached. We must note here that this approximation enables us to transform a molecular property into a sum of local properties. We have called the right side of Eq. (2) the substituent's orientational effect ${ }^{19}$. We have interpreted it (because it originates from the rotational partition function) as giving an account of the relative ease with which the correct drug-receptor alignment for the interaction occurs

When employed within a CNDO/2 level of parametrization, this approach produced excellent QSAR results for very different biologically active molecules ${ }^{14,15,18,20-22}$

The following molecular systems and properties were selected:

a. Classical cannabinoid derivatives (Figure 1): $C B$ binding to rat synaptosomal membranes, $C B_{l}$ binding to African green monkey kidney cells transfected with the cDNA of rat $C B_{1}$ receptor, and $C B_{2}$ binding to COS-7 cells transfected with the cDNA of human $C B$, receptors.

b. Indole-derived cannabinoids (Figure 2): $C B_{1}$ binding to rat brain $\mathrm{P}_{2}$ membranes, and,

c. Aminoalkylindole-derived cannabinoids (Figure 3): Inhibition of $\left[{ }^{3} \mathrm{H}\right]-$ WIN-55212-2 binding to rat cerebellar membranes.

The values for the experimental properties were taken from the literature ${ }^{23-}$ 25 .

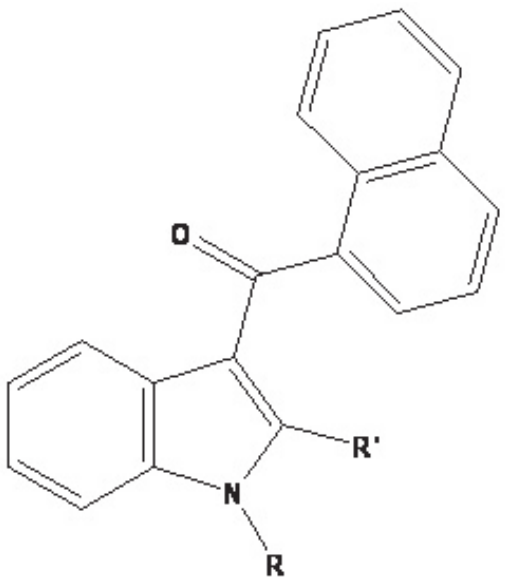
1. $\mathbf{R}=$ ethyl, $\quad \mathbf{R}^{\prime}=$ methyl
2. $\mathbf{R}=$ n-prapyl, $\mathbf{R}^{\prime}=\mathrm{m}$ ethyl
3. $\mathbf{R}=\mathbf{n}$-butyl, $\mathbf{R}$ '= methyl
4. $\mathbf{R}=\mathbf{n}-$ pentyl, $\mathbf{R}^{\prime}=$ methyl
5. $\mathbf{R}=\mathbf{n}$-hexyl, $\quad \mathbf{R}^{\prime}=$ methyl
6. $\mathbf{R}=$ ethyl, $\quad \mathbf{R}^{\prime}=\mathrm{H}$
7. $\mathbf{R}=$ n-prapyl, $\mathbf{R}^{\prime}=\mathrm{H}$
8. $\mathbf{R}=\mathbf{n}$-butyl, $\mathbf{R}^{\prime}=\mathbf{H}$
9. $\mathbf{R}=\mathbf{n}$-pentyl, $\mathbf{R}^{\prime}=\mathbf{H}$
10. $\mathbf{R}=\mathbf{n}-\mathbf{h}$ exyl, $\quad \mathbf{R}^{\prime}=\mathbf{H}$
11. $\mathbf{R}=$ n-heptyl, $\mathbf{R}^{\prime}=\mathrm{H}$

Figure 2. Structure of indole-derived cannabinoids.
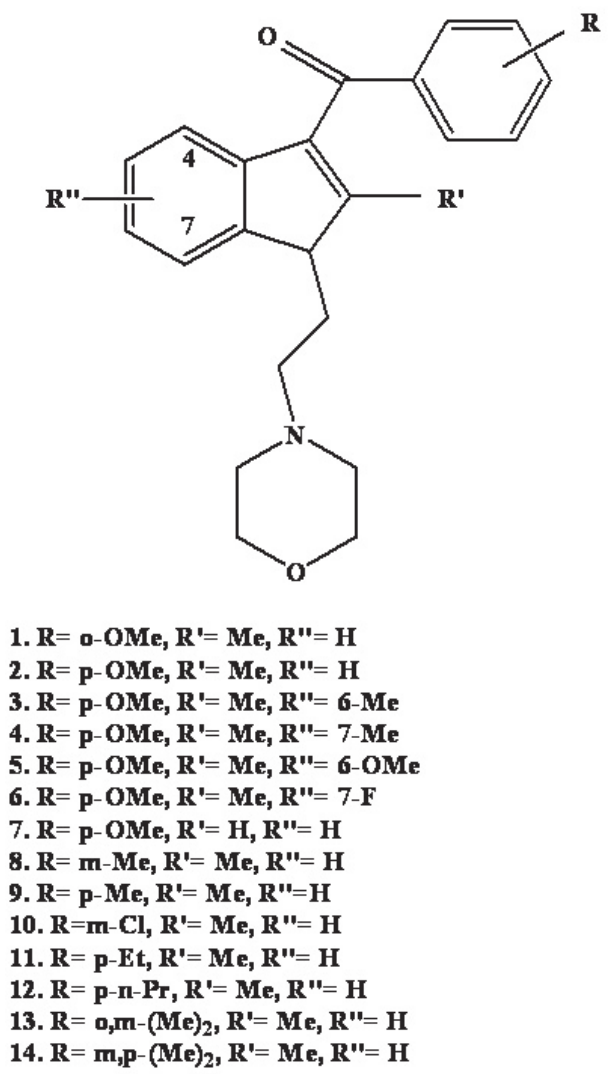

Figure 3. Structure of aminoethylindole-derived cannabinoids.

The molecules were studied in their neutral state. All the calculations were carried out by using the Hyperchem package ${ }^{26}$. Full geometry optimization was carried out using the AM1 semiempirical methodology ${ }^{27}$. The method selected for calculating the wave function was Zerner's ZINDO/128,29. This choice is justified because after AM1 geometry optimization ZINDO/1 is the only method producing positive nucleophilic superdelocalizabilities as required by the model $^{30}$. As expected, ZINDO/1 gave good results when applied to the interaction of a group of 3-substituted morphinans with mu, delta and kappa opioid receptors ${ }^{31}$, and for the $\mathrm{CB}_{1}$ - and $\mathrm{CB}_{2}$-mediated inhibition of adenylyl cyclase by a group of classical cannabinoid derivatives ${ }^{32}$.

It must be noted that the equations for binding affinity were developed from the formal statistical-mechanical definition of the affinity constant. This leads to a system of simultaneous equations that must have a solution if the experimental results are correctly measured and the numerical values of the reactivity indices are calculated with a suitable quantum-chemical method.. To solve this system we must have the same number of experimental results and variables. The problem is that the number of molecules is generally less than the number of unknown quantities. For this reason statistical analysis is employed, not to see if there is a solution, but to find the best one. The statistical fitting of Eq. 1 was performed by means of a stepwise regression technique with the receptor affinities as the dependent variables and the static reactivity indices of the atoms belonging to a common skeleton as independent variables. The common skeleton for classical cannabinoids is shown in Fig. 4. To these variables we added the orientational effect of the substituents placed at positions 6,10 and 12 . For indole-derived cannabinoids the common skeleton is shown in Fig. 5. We added here the orientational effect of the Nsubstituents. For aminoalkylindole-derived cannabinoids the common skeleton is displayed in Fig. 6. We added the orientational effects of the ortho-, meta-, and para-substituents. 


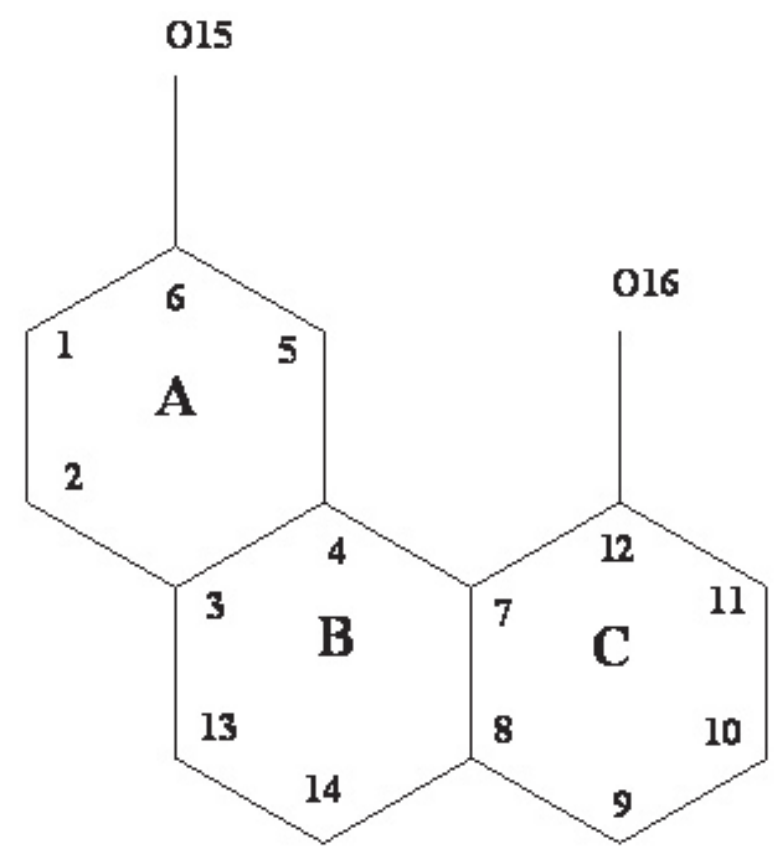

Figure 4. Common skeleton numbering for classical cannabinoids.

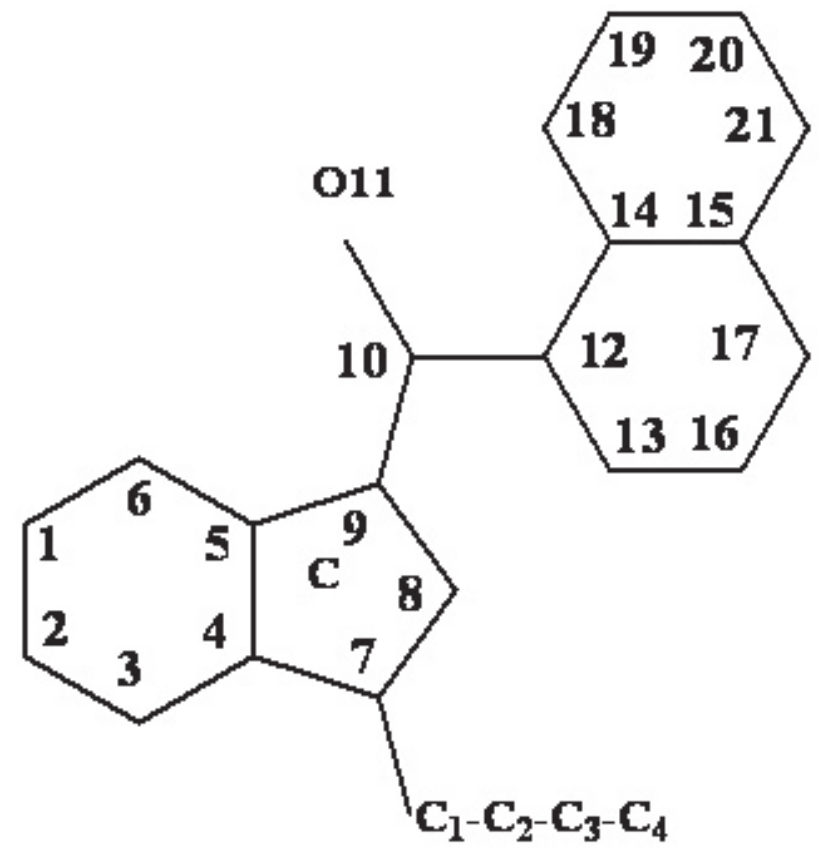

Figure 5. Common skeleton numbering for indole-derived cannabinoids.

\section{RESULTS}

For $C B$ binding of classical cannabinoids to rat synaptosomal membranes the best equation obtained is:

$\log K_{i}=17.69-10.07 Q_{5}+78.77 Q_{9}-6.34 S_{9}^{N /}($ LUMO $)-8.19 D_{10}($ SHOMO $)+0.004 O_{2}-0.0009 O_{3}$

with $\mathrm{R}=0.98$ and $\mathrm{SD}=0.31$. The analysis of variance of Eq. 3 gives $\mathrm{F}(6,6)=25.76(\mathrm{p}<0.001)$, showing that this equation is statistically significant. Here, $Q_{5}$ is the net charge of atom $5, Q_{9}$ is the net charge of atom $9, S_{9}^{N}$ (Lumo) is the orbital nucleophilic superdelocalizability of the LUMO at atom $9, O_{3}$ is the orientational effect of the substituent attached to atom 12, and $O_{3}$ is the same effect for the substituent attached to atom 10 (see Fig. $4 C B_{l}$ ). The predicted $\log K_{i}$ values are shown in Table 1 .

Table 1. Experimental and calculated $\mathrm{CB}_{1}$ receptor affinities of classical cannabinoids to rat synaptosomal membranes.

\begin{tabular}{|c|c|c|}
\hline Molecule $^{a}$ & Experimental log $K^{b}(\mathrm{nM})$ & Calculated log $K^{c}(\mathrm{nM})$ \\
\hline 1 & 2.59 & 2.23 \\
\hline 2 & 0.52 & 0.38 \\
\hline 3 & 2.28 & 2.16 \\
\hline 4 & 0.26 & 0.25 \\
\hline 5 & 2.78 & 2.98 \\
\hline 6 & 0.79 & 0.98 \\
\hline 7 & 2.75 & 2.71 \\
\hline 8 & 1.82 & 1.98 \\
\hline 9 & 0.41 & 0.37 \\
\hline 10 & 1.52 & 1.44 \\
\hline 11 & -0.72 & -0.97 \\
\hline 12 & 2.68 & 2.10 \\
\hline 13 & 1.86 & 1.94 \\
\hline
\end{tabular}

a. See Figure 1. b. Ref. 23 . c. With Eq. 3.

For binding of classical cannabinoids in transfected COS-7 cells the best equation obtained is:

$\log \mathrm{K}_{\mathrm{i}}=-16.94+1.28 \mathrm{~S}_{4}^{\mathrm{N}}(\mathrm{NL}$ TMO $)+1.51 \mathrm{~S}_{7}^{\mathrm{N}}(\mathrm{NL} \mathrm{LMO})+34.89 \mathrm{~S}_{8}^{\mathrm{E}}(\mathrm{NHOMO})+4.92 \mathrm{~S}_{10}^{\mathrm{E}}(\mathrm{SHOMO})+$ $+331.58 \mathrm{~S}_{16}^{\mathrm{H}}-6.57 \mathrm{D}_{16}$ (SHOMO)

with $\mathrm{R}=0.99$ and $\mathrm{SD}=0.27$. The analysis of variance of Eq. 4 gives $F(6,5)=33.46(p<0.001)$, showing that this equation is statistically significant. Here, for example, $S_{8}^{\mathbb{E}}(N H O M O)$ is the orbital nucleophilic superdelocalizability of the second virtual MO at atom 4, $S_{4}^{N}($ NLUMO) is the orbital electrophilic superdelocalizability of the second occupied MO at atom 8 and $s_{10}^{E}$ (SHOMO) is the orbital electrophilic superdelocalizability of the third occupied $\mathrm{MO}$ at atom 10. In Table 2 the calculated $\log K_{i}$ are displayed.

Table 2. Experimental and calculated $\mathrm{CB}_{1}$ receptor affinities of classical cannabinoids in transfected COS-7 cells.

\begin{tabular}{|c|c|c|}
\hline Molecule $^{a}$ & Experimental log $K^{b}(\mathrm{nM})$ & Calculated $\log K^{c}(\mathrm{nM})$ \\
\hline 1 & 2.32 & 2.43 \\
\hline 2 & 0.30 & -0.12 \\
\hline 3 & 1.58 & 1.61 \\
\hline 4 & -1.0 & -0.67 \\
\hline 6 & 0.79 & 0.84 \\
\hline 7 & 1.70 & 1.64 \\
\hline 8 & 1.90 & 1.99 \\
\hline 9 & -0.62 & -0.73 \\
\hline 10 & 1.41 & 1.28 \\
\hline 11 & -1.0 & -0.85 \\
\hline 12 & 1.51 & 1.53 \\
\hline 13 & 1.51 & 1.43 \\
\hline
\end{tabular}
a. Figure 1 .
b. Ref. 23 .
c. With Eq. 4.

For $C B$, binding of indole-derived cannabinoids to rat brain $P_{2}$ membranes no statistically significant equation was obtained for the original common skeleton variables. Upon adding the atomic reactivity indices of the first four carbon atoms of the $\mathrm{N}$ alkyl chain (see Fig. 5; for chains shorter than four 
atoms we used dummy atoms carrying properties set to zero) the best equation obtained was:

$$
\log K_{i}=3.06+4.27 Q_{C 3}-0.27 S_{C 4}^{N}+0.0004 O_{N}
$$

with $\mathrm{R}=0.96$ and $\mathrm{SD}=0.31$. The analysis of variance of Eq. 5 gives $\mathrm{F}(3,7)=$ $24.97(\mathrm{p}<0.001)$, showing that this equation is statistically significant. Here, $O_{N}$ is the orientational effect of the $\mathrm{N}$-substituent (atom 7 of Fig. 6), $Q_{C 3}$ is the net charge of the third carbon atom of the N-alkyl substituent, and $S_{C 4}^{N}$ is the total atomic nucleophilic superdelocalizability of the fourth carbon atom of the N-substituent. The predicted values are shown in Table 3. The results of Student's t-test are: $\mathrm{t}\left[Q_{C 3}\right]=1.80(\mathrm{p} \cong 0.1), \mathrm{t}\left[S_{C 4}^{N}\right]=-8.13(\mathrm{p}<0.0001)$ and $\mathrm{t}\left[O_{N}\right]=3.06(\mathrm{p}<0.02)$. The squares of the internal correlation coefficients are: $r^{2}\left[Q_{C 3}, S_{C 4}^{N}\right]=-0.68, r^{2}\left[Q_{C 3}, O_{N}\right]=0.07$, and $r^{2}\left[S_{C 4}^{N}, O_{N}\right]=-0.13$.

Table 3. Experimental and calculated $C B$ binding of indole-derived cannabinoids to rat brain $P_{2}$ membranes.

\begin{tabular}{|c|c|c|}
\hline Molecule $^{a}$ & Experimental $\log K^{b}(\mathrm{nM})$ & Calculatedlog $K^{c}(\mathrm{nM})$ \\
\hline 1 & 3.07 & 3.12 \\
\hline 2 & 2.21 & 2.59 \\
\hline 3 & 1.34 & 1.06 \\
\hline 4 & 0.98 & 1.09 \\
\hline 5 & 1.68 & 1.31 \\
\hline 6 & 3.14 & 3.12 \\
\hline 7 & 3.02 & 2.59 \\
\hline 8 & 0.95 & 1.05 \\
\hline 9 & 0.95 & 1.09 \\
\hline 10 & 0.99 & 1.30 \\
\hline 11 & 2.11 & 2.01 \\
\hline
\end{tabular}

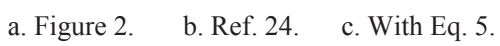

For the inhibition of $\left[{ }^{3} H\right]$-WIN-55212-2 binding to rat cerebellar membranes by aminoalkylindole-derived cannabinoids the best equation obtained is:

$\log K_{i}=-70.05-10.07 D_{1}($ HOMO $)+1.93 S_{14}^{E}+10.08 S_{21}^{N}+27.36 S_{23}^{P}$ (HOMO) $-0.73 S_{25}^{E}($ NHOMO $)$

with $\mathrm{n}=14, \mathrm{R}=0.85, \mathrm{SD}=0.25$ and $\mathrm{F}(5,8)=4.58(\mathrm{p}<0.05)$. Here, for example, $D_{1}(H O M O)$ is the orbital electronic density of the HOMO MO at atom 1, and $S_{14}^{E}$ is the total atomic electrophilic superdelocalizability of atom 14. Table 4 shows the predicted $\log \mathrm{K}_{\mathrm{i}}$ values.

Table 4. Experimental and calculated inhibition of binding to rat cerebellum membranes by aminoalkylindole derived cannabinoids.

\begin{tabular}{|c|c|c|}
\hline Molecule $^{a}$ & $\begin{array}{c}\text { Experimental } \\
\log K^{b}(\mathrm{nM})\end{array}$ & $\begin{array}{c}\text { Calculated } \log K^{b} \\
(\mathrm{nM})\end{array}$ \\
\hline 1 & 2.37 & 2.43 \\
\hline 2 & 2.97 & 2.93 \\
\hline 3 & 2.74 & 2.67 \\
\hline 4 & 2.65 & 2.73 \\
\hline 5 & 2.63 & 2.73 \\
\hline 6 & 2.22 & 2.18 \\
\hline 7 & 2.06 & 2.03 \\
\hline 8 & 2.25 & 2.05 \\
\hline 9 & 2.72 & 2.41 \\
\hline 10 & 2.59 & 2.60 \\
\hline 11 & 1.95 & 2.40 \\
\hline 12 & 2.52 & 2.38 \\
\hline 13 & 2.04 & 1.95 \\
\hline 14 & 1.61 & 1.96 \\
\hline
\end{tabular}

a. See Fig. 3. b. Ref. 25 . c. With Eq. 6 .
For the $\mathrm{CB}_{2}$ binding of classical cannabinoids in transfected COS-7 cells the best equation obtained is:

$\log K_{i}=16.71-1.80 S_{10}^{N}($ LUMO $)-41.83 Q_{12}-2.94 D_{16}($ NHOMO $)-0.006 O_{1}-0.001 O_{3}$

with $\mathrm{n}=12, \mathrm{R}=0.99, \mathrm{SD}=0.23$ and $\mathrm{F}(5,7)=44.88(\mathrm{p}<0.001)$. Here $0_{1}$ and $0_{3}$ are, respectively, the orientational effects of the substituents attached to atom 6 and to atom 10 of the common skeleton (see Fig. 6). Table 5 shows the predicted.

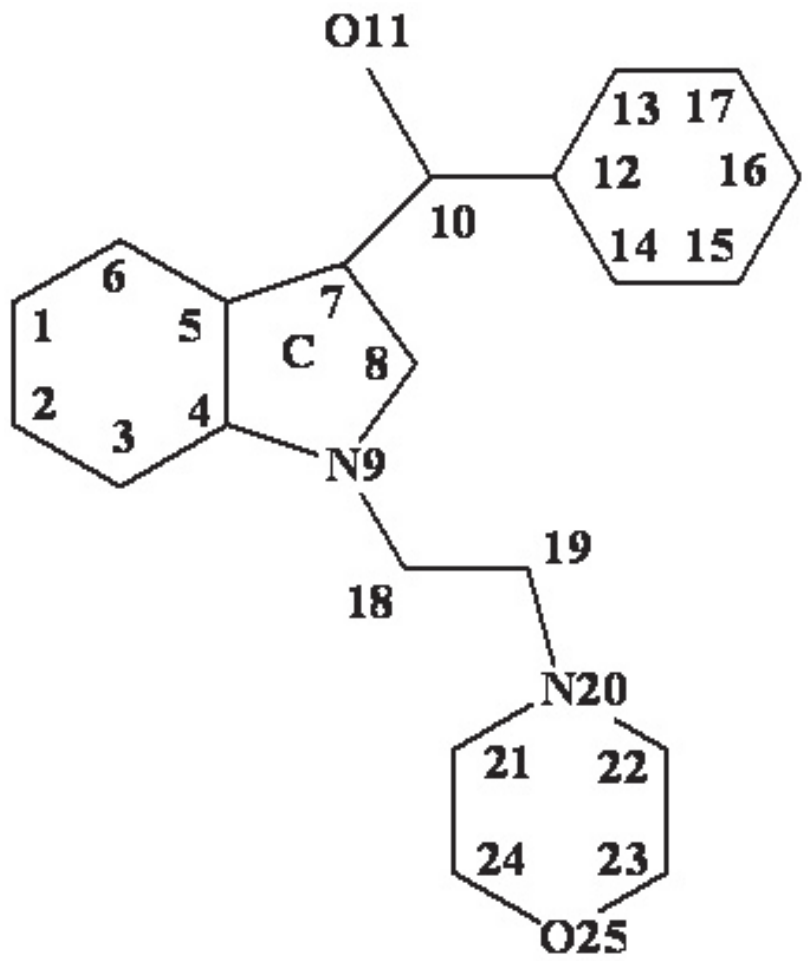

Figure 6. Common skeleton numbering for aminoethylindole-derived cannabinoids.

Table 5. Experimental and calculated $\mathrm{CB}_{2}$ receptor affinities of classical cannabinoids.

\begin{tabular}{|c|c|c|}
\hline Molecule $^{a}$ & $\begin{array}{c}\text { Experimental } \\
\log K^{b}(\mathrm{nM})\end{array}$ & $\begin{array}{c}\text { Calculated } \log K^{b} \\
(\mathrm{nM})\end{array}$ \\
\hline 1 & 2.10 & 1.94 \\
\hline 2 & 0.18 & 0.03 \\
\hline 3 & 1.42 & 1.42 \\
\hline 4 & -0.70 & -0.49 \\
\hline 6 & 0.68 & 0.76 \\
\hline 7 & 1.24 & 1.16 \\
\hline 8 & 1.51 & 1.64 \\
\hline 9 & -0.70 & -0.47 \\
\hline 10 & 0.87 & 0.81 \\
\hline 11 & -0.77 & -1.14 \\
\hline 12 & 2.23 & 2.17 \\
\hline 13 & 1.24 & 1.13 \\
\hline
\end{tabular}

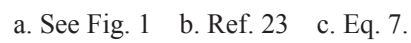




\section{DISCUSSION}

We shall make first some evolutionary considerations. Genes encoding orthologues of the mammalian $C B_{1}$ receptor have been identified in a fish, an amphibian and a bird, indicating that $C B_{1}$ receptors may occur throughout the vertebrates ${ }^{33}$. The zebra finch $C B$, receptor is highly expressed in brain with an amino acid sequence $92 \%$ identical to that of the human $C B_{1}$ receptor $^{34}$. The rat $C B$ receptor shares $97.3 \%$ sequence identity with the human $C B_{1}$ receptor, with $100 \%$ identity within the transmembrane regions ${ }^{35}$.

On the other hand, human and rat cannabinoid $C B_{2}$ receptors only share $81 \%$ amino acid identity ${ }^{36}$. Also, a gene that encodes an ortholog of mammalian receptors $C B_{2}$ was detected in the tropical puffer fish ("Fugu rubripes") ${ }^{37}$.

All this indicates that the gene duplication event that gave rise to $C B_{2}$ and $C B_{2}$ receptors occurred before the divergence of teleosts and tetrapods (350 million years ago).

Finally, the human cannabinoid receptors share only $44 \%$ amino acid identity overall (which rises to $68 \%$ shared identity in the transmembrane domains), yet most ligands do not discriminate between receptor subtypes ${ }^{38}$.

Therefore our QSAR results, obtained from experiments with the rat receptor (for $C B_{1}$ receptors African green monkey kidney cells transfected with rat $C B_{1}$ cDNA, rat brain synaptosomal membrane preparations, rat cerebellar membranes and rat brain $P_{2}$ membranes were used) can be applied to humans if and only if the amino acid sequence and 3D structure of the receptor site at which our molecules bind is conserved in humans and rats..

Our results indicate that the variation of the various receptor affinities analyzed here are related to the variation of a definite set of molecular reactivity indices. We must note that our results concern only in vitro affinities and that nothing can be said about the in vivo pharmacological effects of the compounds studied here. We shall carry out the discussion of the statistical equations by dividing the indices appearing in the equations into two groups. In the first one, we place those indices for which $p$ (Student $) \leq 0.001$ and in the second one the indices for which $\mathrm{p}$ (Student) $>0.001$. Note that the choice of $\mathrm{t}$ is arbitrary. Let us remember that the results of the Student's test are associated with the significance of the individual variables appearing in the different regression equations. The squares of the internal correlation coefficients indicate the percentage of correlation between two given variables.

As the interaction pharmacophore is defined by the atoms and/or group of atoms having the local electronic indices whose variation explains the variation of the affinity constants, analysis of the statistical equations will give a first insight as to its structure. If one or more atoms and/or group of atoms have a constant value for some reactivity indices, they will not appear accounting for the variation of the biological property and will not appear in the structure of the interaction pharmacophore. This is the main reason to carry out QSAR studies for different molecular families in which the position and the nature of the substituents vary.

The $C B$ binding results analyzed here were obtained using tissues containing only $C B_{1}$ receptors. Therefore, we expect the study of the resulting equations to provide some clue features about the cannabinoid- $C B$ receptor interaction. Nevertheless, we must stress that it is not known if the $C B_{1}$ receptors have exactly the same conformation and local atomic environment in all these biological preparations.

The analysis of Eq. 3 (Table 1 and the Supplementary Material) shows that the most relevant variables describing the binding of classical cannabinoids to $C B_{1}$ receptors are a high electron density on atom 10 at the level of the third occupied MO (SHOMO), a high electron accepting capacity of atom 9 at the LUMO level, and a large orientational effect of the substituent attached to atom $10\left(O_{3}\right.$, see Fig. 4). This suggests that the cannabinoid- $C B_{1}$ receptor binding is mainly orbital and sterically-controlled ${ }^{39}$. As atoms 9 and 10 bonded to each other, we may think that they interact with a receptor counterpart composed of two bonded atoms. They can be, for example, a backbone $\mathrm{C}=\mathrm{O}$ group in which one atom acts as an electron donor and the other as an electron acceptor. The requirement of a high value for $O_{3}$ indicates that the cannabinoid molecule needs time and a proper orientation to match the receptor electrostatic potential. The next statistically relevant variables are the net charge of atom 5, that should be positive, and the orientational effect of the substituent attached to atom $12\left(\mathrm{O}_{2}\right)$. A small value for suggests that this orientational effect could modulate the effect of $O_{3}$. The least statistically significant variable is the net charge of atom 9 that should be positive to be in physical agreement with the abovementioned electron accepting capacity of atom 9 .

The analysis of Eq. 4 (see Table 4 and the Supplementary Material) shows that $C B$ binding in transfected COS-7 cells is associated with a high electron accepting capacity of atom 7 at the NLUMO level and a low electron donating capacity of atom 8 at the NHOMO level. The interaction appears to be mainly orbital-controlled. Interestingly, as in the case of Eq. 3 again we find two bonded atoms participating in the $C B_{1}$-ligand interaction. The next statistically relevant variable is a low electron-donating capacity of atom 10 at the SHOMO level. This is not contradictory with the requirement of a high electron density in atom 10 at the level of the same MO in Eq. 3. This is so when a high electron density over the atom is associated with a SHOMO energy lying sufficiently below the HOMO.

Before suggesting a putative structure for the $C B_{1}$ pharmacophore we would like to make some comments. Given the almost $100 \%$ homology of human and rat receptors, the results reported here for rats should be useful for humans. It has been shown that an amino acid located on the extracellular half of the third transmembrane domain of the human $C B_{1}$ receptor, Lys ${ }^{192}$, is essential for the binding of anandamide, CP-55940 and HU-210; but not for the binding of WIN-55212-2 (see Fig. 7). This fact suggests that WIN-552122 must interact with the cannabinoid receptor through at least one point of interaction that is distinct from those of the three other agonists ${ }^{40}$. Moreover, when Lys is mutated to an Ala, HU-210, CP-55940, and anandamide failed to compete for $\left[{ }^{3} \mathrm{H}\right]-\mathrm{WIN}-55212-2$ binding to the mutant cannabinoid receptor ${ }^{40}$. This indicates that the charged amine residue is necessary for cannabinoid binding. We suggest that Lys could interact with O16 of Fig. 4 through a hydrogen bond because lysines are often found buried with only the amino group exposed to solvent.

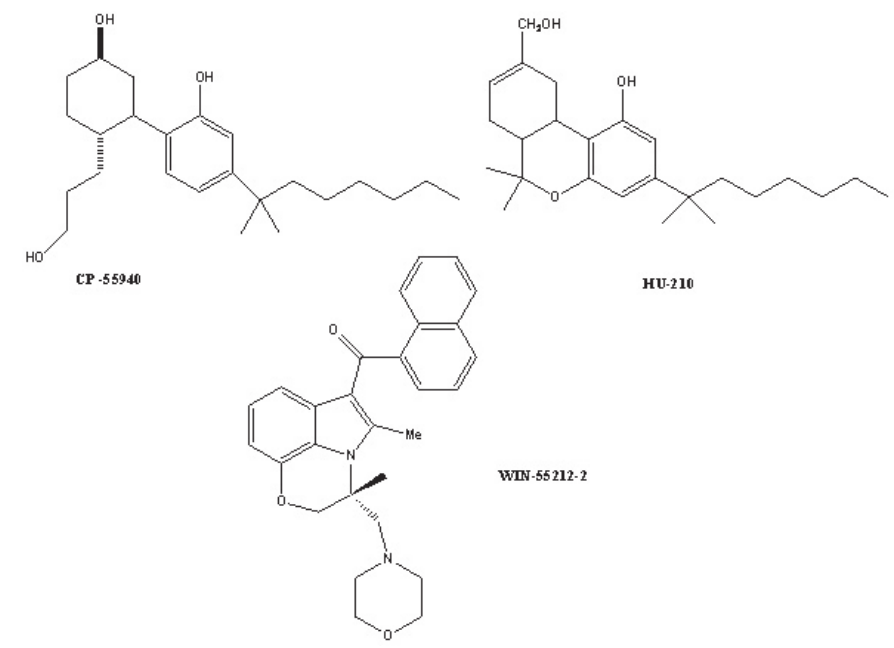

Figure 7. CP-55940, HU-210 and WIN-55212-2.

On the other hand, it has been suggested from molecular dynamics simulations that a ligand conformational change in CP-55244 (see Fig. 8), induced by rotating around a couple of dihedral angles, allows the $\mathrm{C} 10$ side chain (see Fig. 4) to trigger a $C B_{1}$ receptor conformational change. This conformational change could be a major driving force leading to G-protein activation ${ }^{41}$. We are of the opinion that such a conclusion is a loose one. To support this hypothesis a study should be carried out at least with some classical cannabinoids carrying a pentyl chain at C10 and with anandamide. As we have shown above, the $\mathrm{C} 10$ side chain orientational parameter contribution should be high for a better affinity. This is achieved with the most extended conformation. Besides, given the high selectivity of cannabinoid receptors achieved through several hundred of million years, it is doubtful that a simple conformational change of the dimethylheptyl chain (DMH) should be responsible for such an important chain of events.

The high number of variables related to ring $C$ appearing in Eq. 3 and 4 strongly suggests that this ring must be fully aromatic. On the other hand, we must consider that ring A in Fig. 4 does not need to be fully aromatic, as is shown by the affinities of molecules 8-12 of Fig. 1 and Table 1. Moreover, molecules such as CP-55940 and CP-55244 present an equivalent fully saturated A ring. Thus, $\pi$ electrons on this ring are not needed for interaction with $C B_{1}$ receptors. 

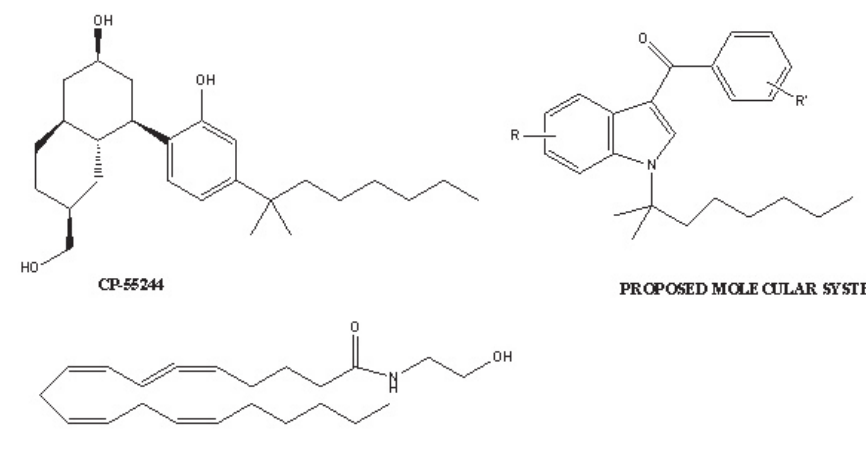

ANANDAMIDE

Figure 8. CP-55244, anandamide and a proposed molecular system.

Figure 9 displays a proposal of a $C B_{1}$ pharmacophore encompassing the main results of Eq. 3 and 4 and the above comments.

Equation 5 is a very interesting case. No statistically significant equation was obtained by using atomic reactivity indices for the common skeleton depicted in Fig. 2. This surely indicates that all the variables belonging to this skeleton which participate in the ligand-C $C B_{1}$ receptor interaction are constant. Equation 5 (see Table 3) only allows us to suggest that the $\mathrm{N}$-alkyl chains could participate in the interaction with the receptor through dispersion forces and through their conformational state at the interaction time. In any case, as Eq. 5 shows, these effects are very small. However, we can make the following considerations. The first one is that in this family only the carbonyl oxygen could $\mathrm{H}$ bond to Lys. If this is so, then the pyrrole ring (C in Fig. 5) and the Nalkyl chain are equivalent, respectively, to ring $\mathrm{C}$ and to the n-pentyl chain at $\mathrm{C} 10$ of classical cannabinoids. As to this date we have not been able to include formally dispersion forces and static polarizabilities in our QSAR model, we think that $Q_{C 3}$ and $S_{C 4}^{N}$ approximate a representation of these effects. This

effect was included in Fig. 9 under "dispersion forces" close to the DMH chain. More experimental and theoretical work is needed to solve this interesting problem.

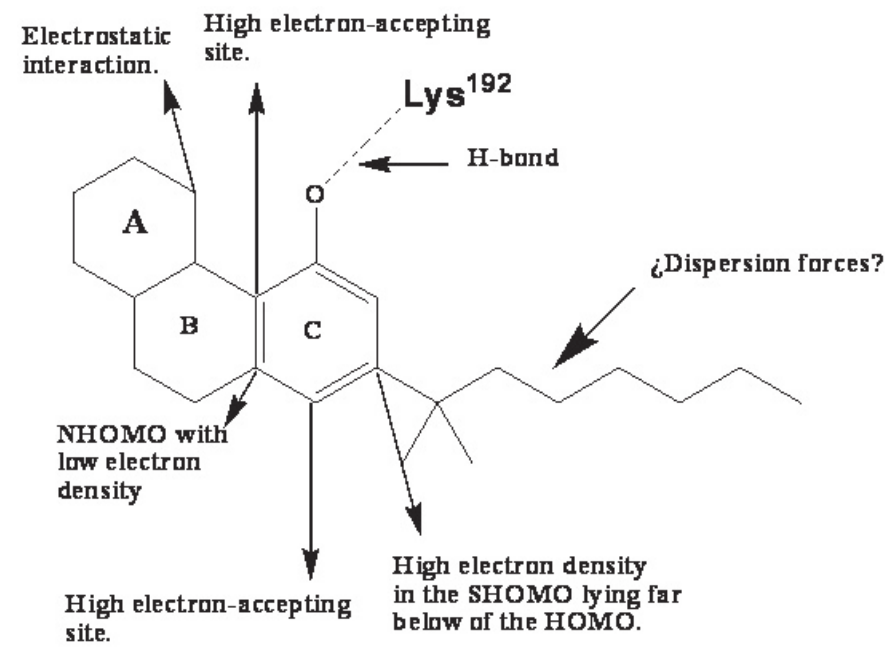

Figure 9. Proposed pharmacophore for classical cannabinoids interacting with $C B_{1}$ receptors.

The analysis of Eq. 6 (see Table 4 and the Supplementary Material) shows that the variation of the receptor affinity appears to be mainly orbital-controlled, but we must note that equation 6 is statistically poor. This is explained by the fact that the experimental set of values selected for the regression analysis only covers a small range of values. Therefore, regression analysis is trying to explain small variations in affinity that can be part of the experimental error. There is another very interesting and puzzling fact that we shall comment on. First, we must notice that this molecular family is structurally similar to WIN-55212-2 (Fig. 7). Second, WIN-55212-2 binds to the cannabinoid receptor through at least one point of interaction that is distinct from those of other agonists. Now, if we examine equations 5 and 6 and their corresponding skeletons (Figs. 5 and 6) we find that it is possible to make a correspondence between $S_{C 4}^{N}$ of Eq. 5 and of Eq. 6. For these reasons we suggest that the ethylmorpholine fragment is equivalent to the DMH side chain of classical cannabinoids and that oxygen 25 (the morpholine oxygen) is the atom through which WIN-55212-2 binds to the site that is not available to classical cannabinoids and anandamide. This second site, then, is located not far from the DMH chain and interacts through a $\mathrm{H}$ bond. If this is correct, then the proposed molecular system depicted in Fig. 8 should display a binding profile similar to that of classical cannabinoids. After the above orientation and alignment rules have been defined as a basis for the comparison of noncongeneric molecules, it should be possible to associate the localization of molecular fragments of these systems with known molecular systems such as classical cannabinoids. These associations are depicted in Fig. 10. This seems to be more than a coincidence because our preliminary QSAR results for the interaction of arachidonic acid derivatives with cannabinoid receptors indicate that the net charges of the carbon chain are statistically relevant variables (Gómez-Jeria et al., unpublished results).

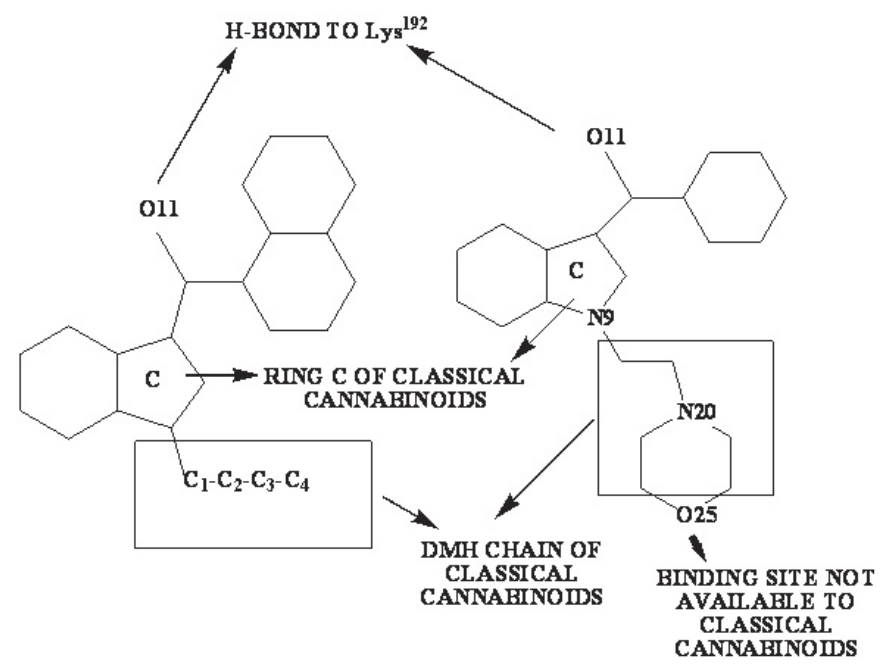

Figure 10. Proposed structural relationships between indole-derived cannabinoids, aminoalkylindoles and classical cannabinoids.

The variation of the affinity of classical cannabinoids for $C B_{2}$ receptors in transfected COS-7 cells is shown in Eq. 7. The interaction is mainly controlled by a large orientational effect of the substituent attached to atom $10\left(O_{3}\right.$, see Fig. 4) and a good electron accepting capacity of atom 10 at the LUMO level.

The high value for the $O_{3}$ orientational effect seems to be common to $C B_{1}$ (see Eq. 3) and $\mathrm{CB}_{2}$ receptors. A long time ago the increase in pharmacological activity associated with the replacement of the pentyl group at position 10 in Fig 4 by a 1,1-dimethylheptyl substituent was noted ${ }^{42}$. We may hypothesize that, if the $O$, orientational effect is really a statistically relevant variable for both cannabinoid receptors, then it is a property that has been conserved for about 400 million years

The appearance of $S_{10}^{\mathrm{N}}(\mathrm{LUMO})$ is compatible with a low electron-donating capacity of atom 10 at the SHOMO level as discussed earlier. The next relevant variables are a high value for the orientational effect of the substituent attached to atom $6\left(\mathrm{O}_{1}\right.$, see Fig. 4), a positive net charge on atom 12 and a high electron density of the NHOMO on atom $16 . \mathrm{O}_{1}$ does not appear in $C B_{1}$ related equations. If this property helps to differentiate ligand binding to both cannabinoid receptors it should be a phylogenetically newer $C B_{2}$ characteristic. A positive net charge on atom 12 is consistent with an $\mathrm{O}$ atom bonded to it. A high value for the electronic density of the NHOMO of atom 16 is indicative of the participation of the oxygen atom as an electron donor, maybe through a $\mathrm{H}$ bond.

Interestingly, and contrary to the case of $C B$ receptors, when the lysine residue of the extracellular half of the third transmembrane domain of the human $C B_{2}$ receptor is mutated to an alanine residue, the receptor's ability to recognize anandamide, WIN-55212-2, CP-55940, cannabinol and $\Delta^{9}-\mathrm{THC}$ is maintained. Only when the serine residue, unique to the $C B$, receptor, was mutated to glycine in the alanine mutant, this double mutant retains the ability to bind aminoalkylindoles but loses affinity for classical cannabinoids ${ }^{43}$. These 
results could indicate that, in $\mathrm{CB}_{2}$ receptors, the lysine residue lost its $\mathrm{H}$-bonding function being replaced by a serine residue, probably at a close location. Also, it seems that aminoalkylindoles bind to a second site that is not available to classical cannabinoids as in the case of $C B$, receptors. These differences in the mode of binding of cannabinoids to $C B_{1}$ and $C B_{2}$ receptors are also clearly shown by the QSAR results for cannabinoid-mediated inhibition of adenylyl cyclase $^{32}$.

\section{CONCLUSIONS}

We have shown, starting from a model-based method $^{44}$, that the in vitro binding of classical cannabinoids to $C B_{1}$ and $C B_{2}$ receptors seems to be regulated by different mechanisms. In indole-derived cannabinoids the pyrrole ring and the $\mathrm{N}$-alkyl chain are equivalent, respectively, to aromatic ring $\mathrm{C}$ and to the n-pentyl chain of classical cannabinoids. In aminoalkylindole-derived cannabinoids the ethylmorpholine fragment is equivalent to the pentyl side chain of classical cannabinoids. In aminoalkylindole-derived cannabinoids the morpholine oxygen is the atom through which WIN-55212-2 and analogous molecules bind to the site that is not available to classical cannabinoids and anandamide.

Supplementary Material. A pdf file containing all the statistical results for each QSAR equation is available.

Acknowledgments: We are grateful to the Department of Chemistry, Faculty of Sciences, University of Chile, for partial financial help.

\section{REFERENCES}

1. E.A. Abel Marijuana: The First 12,000 Years; Plenum Press, New York, 1980.

2. C. Hale Himmler's crusade; New Jersey, John Wiley \& Sons, 2003.

3. A.C. Howlett, F. Barth, T.L. Bonner, G. Cabral, P. Casellas, W.A. Devane, C.C. Felder M. Herkenham, K. Mackie, B.R. Martin, R. Mechoulam, R.G. Pertwee, Pharmacol. Rev. 54, 161 (2002)

4. M. Herkenham in Cannabinoid Receptors; Pertwee, E. Ed.; Harcourt Brace \& Co., London, 1995; p. 145.

5. R.G. Pertwee, Pharmacol. Ther. 74, 129 (1997)

6. S. Galiegue, S. Mary, J. Marchand, D. Dussossoy, D. Carriere, P. Carayon, M. Bouaboula, D. Shire, G. Le Fur, P. Casellas, Eur. J. Biochem. 232, 54 (1995)

7. W.A. Devane, L. Hanus, A. Breuer, R.G. Pertwee, L.A. Stevenson, G. Griffin, D. Gibson, A. Mandelbaum, A. Etinger, R. Mechoulam, Science 258, $1946(1992)$

8. Z. Vogel, J. Barg, R. Levy, D. Saya, E. Heldman, R. Mechoulam, J. Neurochem. 61, 352 (1993)

9. E. Di Tomaso, M. Beltramo, D. Piomelli, Nature 282, 677 (1996)

10. F. Desarnaud, H. Cadas, D. Piomelli, J.Biol. Chem. 270, 6030 (1995)

11. V. Di Marzo, N. Sepe, L. De Petrocellis, A. Berger, G. Croziert, E. Fride, R. Mechoulam, Nature 396, 636 (1998)

12. M. Beltramo, D. Piomelli, Nature 396, 636 (1998)

13. J.S. Gómez-Jeria, Int. J. Quantum Chem. 23, 1969 (1983)

14. J.S. Gómez-Jeria, M. Ojeda-Vergara, Int. J. Ouantum Chem. 61, 997 (1997)

15. J.S. Gómez-Jeria, L. Lagos-Arancibia, Int. J. Quantum Chem. 71, 505 (1999)
16. J.S. Gómez-Jeria in Molecules in Physics, Chemistry and Biology; Maruani, J Ed.; Kluwer, Dordrecht, 1989, Vol. 4; p. 215.

17. F. Soto-Morales, J.S. Gómez-Jeria, J. Chil. Chem. Soc. 52, 1214 (2007)

18. J.S. Gómez-Jeria, C. Donoso-Espinoza, M. Ojeda-Vergara, Mol. Engn. 5, 391 (1995)

19. J.S. Gómez-Jeria, M. Ojeda-Vergara, J. Chil. Chem. Soc. 48, 119 (2003)

20. J.S. Gómez-Jeria, P. Sotomayor, J. Mol .Struct. (Theochem) 166, 493 (1988)

21. J.S. Gómez-Jeria, D. Morales-Lagos, B.K. Cassels, J.C. Saavedra-Aguilar, Quant. Struct. Act. Relat. 5, 153 (1986)

22. J.S. Gómez-Jeria, B.K. Cassels, J.C. Saavedra-Aguilar, Eur. J. Med. Chem. 22, 433 (1987)

23. M-H. Rhee, Z. Vogel, J. Barg, M. Bayewitch, R. Levy, L. Hanus, A. Breuer, Mechoulam, R. J. Med. Chem. 40, 3228 (1997)

24. J.L. Wiley, D.R. Compton, D. Dai, J.A.H. Lainton, M. Phillips, J.W. Huffman, B.R. Martin, J. Pharmacol. Exptl. Ther. 285, 995 (1998)

25. M.A. Eissensat, M.R. Bell, T.E. D’Ambra, E.J. Alexander, S.J. Daum, J.H. Ackerman, M.D. Gruett, V. Kumar, K.G. Estep, E.M. Olefirowicz, J.R. Wetzel, M.D. Alexander, J.D. Weaver III, D.A. Haycock, D.A. Luttinger, F.M. Casiano, S.M. Chippari, J.E. Kuster, J.L. Stevenson, S.J. Ward, J. Med. Chem. 38, 3094 (1995)

26. Hyperchem, V. 5.01. Hypercube Inc. 419 Phillip St., Waterloo, Ontario, Canada.

27. M.J.S. Dewar, E.G. Zoebisch, E.F. Hely, J.J.P. Stewart, J. Am. Chem Soc. 107, 3902 (1985)

28. W.D. Edwards, M.C. Zerner, Theoret. Chim. Acta 72, 347 (1987)

29. W.P. Anderson, W.D. Edwards, M.C. Zerner, Inorg. Chem. 28, 2728 (1986)

30. J.S. Gómez-Jeria, J. Pharm. Sci. 71, 1423 (1982)

31. J.S. Gomez-Jeria, L.A. Gerli-Candia, S.M. Hurtado, J. Chil. Chem. Soc 49, 307 (2004)

32. J.S. Gómez-Jeria, F. Soto-Morales, G. Larenas-Gutierrez, Iranian Int. J. Sci. 4, 151 (2003)

33. M.R. Elphick, M. Egertova, Philos. Trans. R. Soc. Lond. 356, 381 (2001)

34. K. Soderstrom, F. Johnson, J. Pharmacol. Exptl. Ther. 297, 189 (2001)

35. C.M. Gérard, C. Mollereau, G. Vassart, M. Parmentier, J. Biochem. 279, 129 (1991)

36. S. Mukherjee, M. Adams, K. Whiteaker, A. Daza, K. Kage, S. Cassar, M Meyer, B.B. Yao, Eur. J. Pharmacol. 505, 1 (2004)

37. M.R. Elphick, Biol. Bull. 202, 104 (2002)

38. S. Munro, K.L. Thomas, M. Abu-Shaar, Nature 365, 61 (1993)

39. I. Fleming, I. Frontier Orbitals and Organic Chemical Reactions; John Wiley \& Sons, New York, 1976.

40. Z-H. Song, T.I. Bonner, Mol. Pharmacol. 49, 891 (1996)

41. J-H. Shim, A.C. Howlett, J. Chem. Inf. Comput. Sci. 44, 1466 (2004)

42. R. Adams, S. Mackenzie Jr., S. Loewe, J. Am. Chem. Soc. 70, 664 (1948)

43. Q. Tao, S.D. McAllister, J. Andreassi, K.W. Nowell, G.A. Cabral, D.P. Hurst, K. Bachtel, M.C. Ekman, P.H. Reggio, M.E. Abood, Mol. Pharmacol. 55, 605 (1999)

44. Y.C. Martin, Quantitative Drug Design; Dekker, New York, 1978. 